\title{
REAL TIME BASED SMART VEHICLE MONITORING AND ALERT USING GSM
}

\author{
S.Boopathi ${ }^{1}$, K.Govindaraju $^{1}$, M.Sangeetha $^{1}$, M.Jagadeeshraja $^{2}$, M.Dhanasu $^{3}$ \\ PG Student, Embedded System Technologies, Knowledge Institute of Technology, Salem, India ${ }^{1}$ \\ Assistant professor, Department of EEE, Knowledge Institute of Technology, Salem, India ${ }^{2}$ \\ Assistant General Manager(CEM).Salem Steel Plant,India ${ }^{3}$
}

\begin{abstract}
Human life is more valuable than anything else, timely help is more important than lending a helping hand. In during accidents, people lose their lives due to delay of proper medical facilities at the right time. This proposed system senses any accident in the vehicle and intimates pre-programmed numbers like the owner of the vehicle, ambulance, police etc. The GSM technology is used to send the position of the vehicle as a SMS to those numbers and the position of the vehicle can be obtained by the owner of the vehicle and also only car meet with in accident but human life is safe so there is no needed emergency at the place in proposed method, we are using small switching function(reset) for disconnecting the signal and when a car meets an accident, wait for some mines and immediately the car and the GPS co-ordinate of the location are messaged to the nearby hospitals ,thereby ensuring timely help to the needy.
\end{abstract}

Keywords: ARM processor, GSM, GPS.

\section{INTRODUCTION}

This human life is very valuable one and The person travelling can be tracked and also secured in the case of an emergency. On the other hand safety has also become a major factor that is to be taken care of which numbers of accidents have rapidly increased day by day, many lives are lost due to improper post-accident signaling and tracing out the exact location and mainly used to track the position of the Vehicle by the police or emergency can also be used in the public transportation system by the people to know the location of the vehicles. In case of any accident, the system sends automated messages to the preprogrammed numbers. We can send messages to any number of mobiles. The owner of the vehicle, Police to clear the traffic, Ambulance to save the people can be informed by this device. This uses a GPS (Global Positioning System) to know the exact position of the vehicle with an accuracy of a few feet. GSM is used to receive SMS from the user and reply the position of the vehicle through a SMS. A ARM is used to control and coordinate all the parts used in this system. When there is any accident, an accelerometer sensor is triggered and it sends signal to the ARM. The ARM circuit processes the input and sends the appropriate output according to the programming done. It also sends a message to police control room with the location of accident to minimize the time required for legal police process, and a victim can get fast treatment. It also provides facility to refuse the medical treatment if victim is not badly injured to save the valuable time of medical rescue team. One more facility is provided that in a case when a person no need medical treatment at the time a message is not transmitted to the medical help center by just pressing single switch.

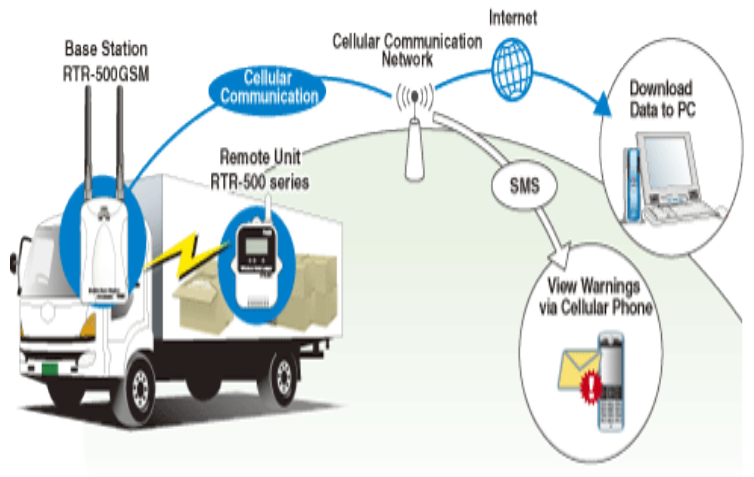

Fig.1.Gsm Communication

\section{LITERATURE SURVEY}

Chen,H.Chiang et al,The GPS/GSM Based System is one of the most important systems, which integrate both GSM and GPS technologies. It is necessary due to the many of applications of both GSM and GPS systems and the wide usage of them by millions of people throughout the world [1].

Prof. Zing $\mathrm{Xu}$ et al, it is discusses a vehicle to vehicle Location-Based Broadcast communication protocol, in which each vehicle generates emergency messages at a constant rate. Message forwarding can help warning message reach vehicles beyond the radio transmission range. The authors propose a multi-hop broadcast protocol based on slot reservation MAC. Motion properties of vehicles are used to help with message relay. Two 
protocols to reduce the amount of forwarding messages were proposed [2].

Albert Alexe et al,The sensors are used to monitor the fuel level, driver conditions, and speed of the vehicle. All the data transferred to cloud server-using GSM enabled device. All the vehicles equipped with GPS antenna to locate the place. To avoid the drunk and drive, the alcohol sensor installed to monitor the driver status. The proposed technology significantly avoids the accident in highways [3].

Mohan R Akella et al,It will provide an optimum solution to this draw back. An accelerometer can be used in a car alarm application so that dangerous driving can be detected. It can be used as a crash or rollover detector of the vehicle during and after a crash. With signals from an accelerometer, a severe accident can be recognized. According to this project when a vehicle meets with an accident immediately Vibration sensor will detect the signal or if a car rolls over, and Micro electromechanical system (MEMS) sensor will detects the signal and sends it to ARM processor. ARM sends the alert message through the GSM MODEM including the location to police control room or a rescue team[3][4].

Nirav Thakor et al.we describe a real-time online safety prototype that controls the vehicle speed under driver fatigue. The purpose of such a model is to advance a system to detect fatigue symptoms in drivers and control the speed of vehicle to avoid accidents [5].

S.P. Bhumkar et al, It is providing a solution to this in which a mobile stand where driver should have to place his cell phone. If the driver doesn't do so then the ARM starts its working accordingly and tend driver to stop the car and then continue the conversation on cell-phone, which leads to the least chances of happening of an accident. In another case if road mishaps took place, this project sends emergency message to the rescue teams and surrounding people to save the life of victims[6][7].

V.Ramya,et al, To achieve a design of such system that can give information of the vehicle position every time there's a request for it. Safety and security is a major concern for all vehicle owners[8].

ying-wen et al, This vehicle tracking system ensures safety and security of vehicle by tracking its position and sending it to owner or any people whenever it is requested by [9][10].

\section{BLOCK DIAGRAM}

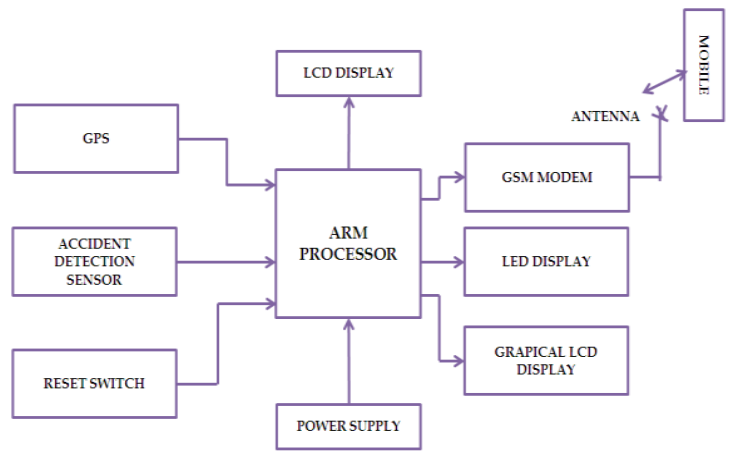

Fig.2. Proposed Block Diagram

\subsection{Block diagram description}

From the figure the proposed system consists of different modules which are interfaced to the ARM (32 bit) controller. The input power is step down to $12 \mathrm{v} \mathrm{DC}$ from 230v AC power line by the power supply unit. The main module is the ARM processor having the high speed processing of the data because of the pipelining instruction bit of handling technique and ability to be used as a 16 bit controller. Whenever the accident occurs the vibrations are sensed by the vibration sensor and these signals are given to the controller through the amplifying circuit and when the input is received by the controller, the buzzer (alarm) is $\mathrm{ON}$ and the message is sent to the rescue team with the help of the GSM technology. The rescue team reaches the site of the accident with the help of the location given in the message. The location or the geographical coordinates where the vehicle is present are detected by the GPS technology. In some conditions where there are no casualties or when there is no need of the medical facility to the person, then the messaging can be terminated with the help of the switch provided in order to avoid wasting the valuable time of the medical rescue team. The GSM and GPS modules are interfaced to the ARM processor using serial communication. All the components are interfaced precisely so that the accident detection and alert message sending are fully automated, so that the warning time is reduced significantly.

\section{A.GSM (Global System for Mobile communications):}

The GSM (Global System for Mobile communications) is an open, digital cellular technology used for transmitting mobile voice and data services. GSM differs from first generation wireless systems in that it uses digital technology and time division multiple access transmission methods. GSM is a circuit-switched system that divides each $200 \mathrm{kHz}$ channel into eight $25 \mathrm{kHz}$ time-slots; GSM supports data transfer speeds of up to $9.6 \mathrm{Kbit} / \mathrm{s}$, allowing the transmission of basic data services such as SMS (Short Message Service). Another major benefit is its international roaming capability, allowing users to access the same services when traveling abroad as at home. This 
gives consumers seamless and same number connectivity in more than 210 countries. GSM satellite roaming has also extended service access to areas where terrestrial coverage is not available.

\section{B. Global positioning system (GPS):}

The Global Positioning System (GPS) is a space-based satellite navigation system that provides location and time information in all weather conditions, anywhere on or near the Earth where there is an unobstructed line of sight to four or more GPS satellites. The system provides critical capabilities to military, civil and industrial and commercial users around the world.

\section{Accident monitoring:}

Crash sensors are placed on the chassis of the car, this crash sensor is capable of sensing the force produced by an accident i.e. in terms of ' $G$ ' ( $G$ - Force against gravity). Once the force is greater than or equal to the threshold value set on the sensor, the sensor produces an output which in turn is amplified by a signal conditioning unit, normally a CE mode amplifier acts as a signal conditioner. Finally the signal is sent to the ARM, and there by triggering the GSM modem to shoot out an SMS to the near-by hospitals along with the GPS co-ordinates.

\section{D.Vibration sensor:}

The Accelerometers are sensors or transducers that measure acceleration. Accelerometers generally measure acceleration forces applied to a body by being mounted directly onto a surface of the accelerated body.

Accelerometers are useful in detecting motion in objects. This motion is indicative of motion in the larger object application in which the accelerometer is mounted. Thus, a sensitive accelerometer can quickly detect motion in the application.

The accelerometer is connected with ARM and placed in vehicle. If any accident occurs in the highways, the accelerometer sensor (vibration sensor) will indicate the controller and controller will in turn transmit the message to the hospitals and police stations through GSM technology

\section{E.Flow chart:}

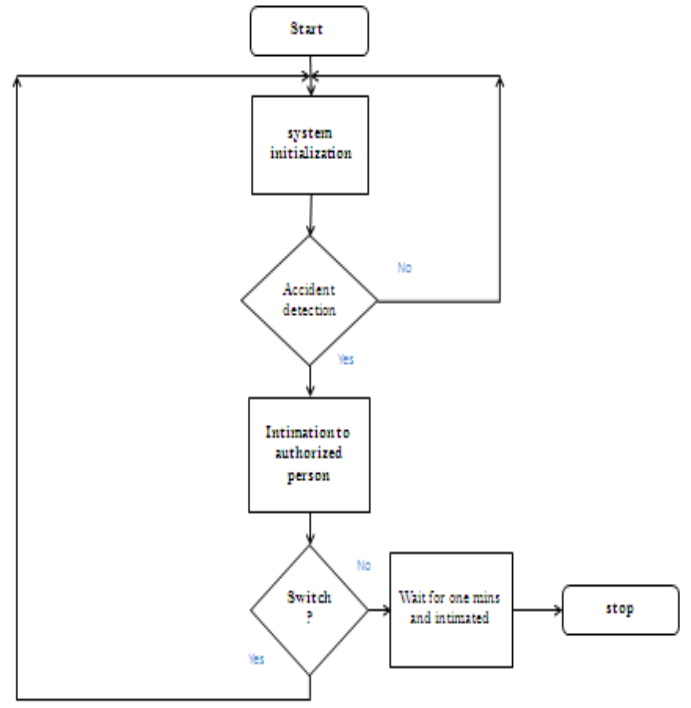

Fig-3: Flow Chart for Proposed System IV.HARDWARE IMPLEMENTATION

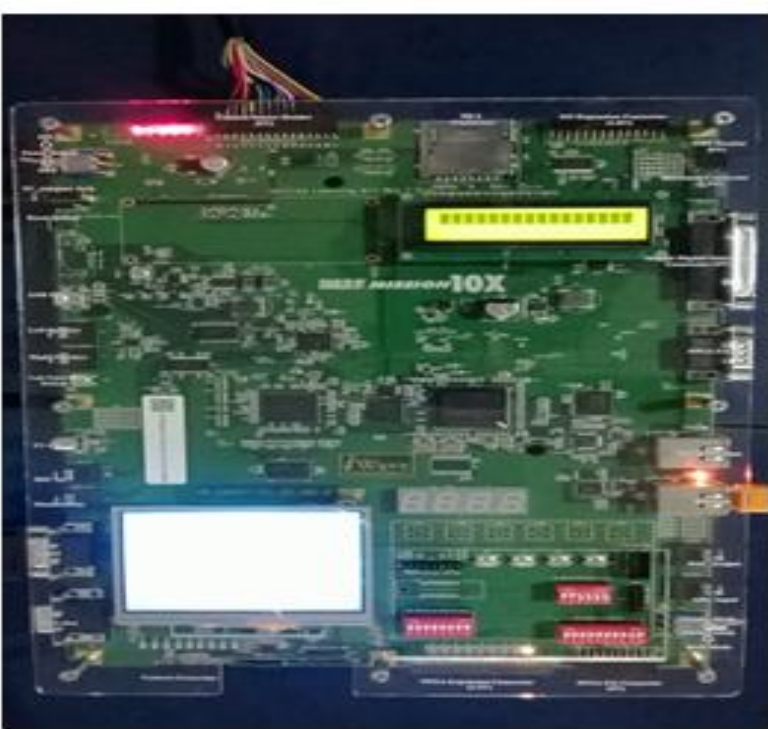

Fig-4: UTLP Kit

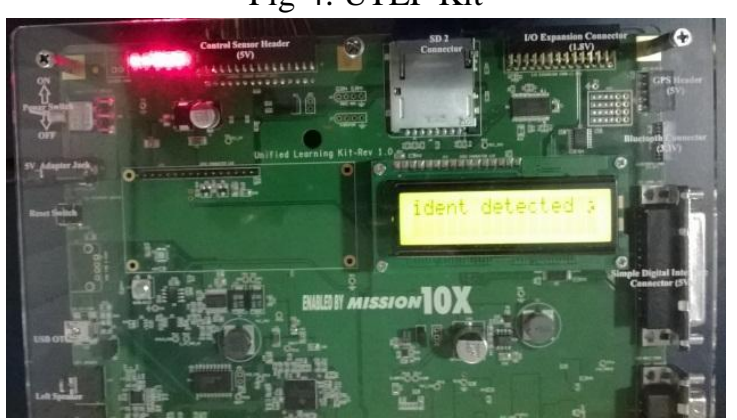

Fig-5: Accident Detected 
International Journal of Advanced Research in Computer and Communication Engineering Vol. 3, Issue 11, November 2014

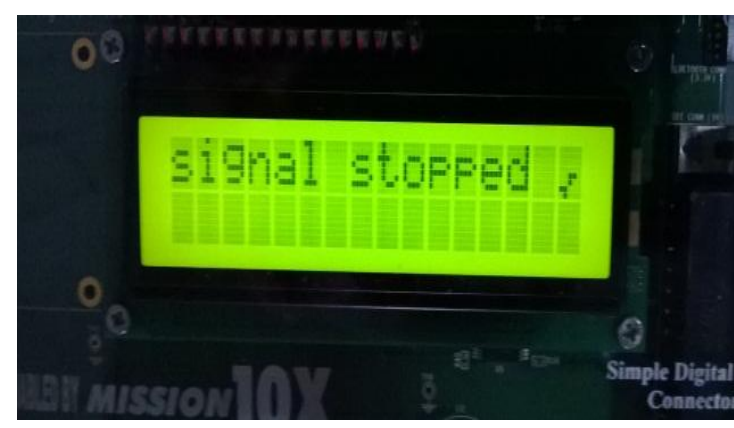

Fig-6: Signal Stopped

\section{V.CONCLUSION}

As the system is designed for this has the advantages of low cost, portability, small size and easy expansibility. The platform of the system is ARM along with GPS and GSM, interfacing which shortens the alarm time to a large extent and locate the site of accident accurately. This system can overcome the problems of lack of automated system for accident location detection. Also in case of road mishaps to provide the real time help to the victims we have designed a user-friendly kit which provides the real time information about the accident to the victim's relative as well to the nearby passing vehicles and surrounding people for proving a quick medical help. At the same time our system provides the accident information to emergency and Police Control room. In some conditions where there is no need of the medical facility to the messaging can be terminated with the help of the switch provided in order to avoid wasting the valuable time of the medical rescue team.

\section{REFERENCES}

1. Chen, H., Chiang, Y. Chang, F., H. Wang, H. (2010). Toward RealTime Precise Point Positioning: Differential GPS Based on IGS Ultra Rapid Product, SICE Annual Conference, The Grand Hotel, Taipei, Taiwan August 18-21.

2. Prof. Zing Xu: V-V location Based broadcast communication, Automated crash notification via the wireless web: system design and validation", vol. 19, no. 6, pp. 1048-1059, 2011

3. Albert Alexe, R.Ezhilarasie, "Cloud Computing Based Vehicle Tracking Information Systems", ISSN: 2229 - 4333 ( Print) | ISSN: 0976 - 8491 (Online) IJCST Vol. 2, Iss ue 1, March 2011.

4. Mohan R Akella, Wireless vehicular Accident Detection and Reporting System, vol. 95, no. 2, pp. 388-396, 2007

5 .Nirav Thakor, Tanmay Vyas, Divyang Shah, "Automatic Vehicle Accident Detection System Based on ARM \&GPS", International Journal for Research in Technological Studies ISSN: - Applied (Online) Vol-1, Issue - 1, Dec 2013.

6. S.P. Bhumkar, V.V. Deotare, R.V.Babar, " Intelligent Car System for Accident Prevention Using ARM-7", International Journal of Emerging Technology and Advanced engineering ISSN 22502459, Volume 2, Issue 4, April 2012

7. Prof. Abhay P. Bagade, "Cell Phone Usage While Driving Avoidance with GSM-RF Based Accident Emergency Alert System", ISSN (Print) : 2319-5940 ISSN (Online) : 2278-1021, Vol. 2, Issue 5, May 2013 International Journal of Advanced Research in Computer and Communication Engineering.

8. V.Ramya, B. Palaniappan, K. Karthick, "Embedded Controller for Vehicle In-Front Obstacle Detection and Cabin Safety Alert
System", International Journal of Computer Science \& Information Technology (IJCSIT) Vol 4, No 2, April 2012.

9. Design and implementation of a fall monitor system by using a 3axis accelerometer in a smart phone, IEEE- 2012. By ying-wen bai.siao-cianwu, cherig-lung tsainovember 2012

10. Steve Furber, ARM system-on-chip architecture, second edition, Pearson Education Limited,2000.

\section{BIOGRAPHY}

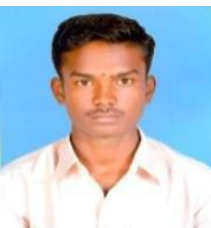

S.Boopathi is pursuing, $\mathrm{PG}$ in the discipline of Embedded System Technologies at Knowledge Institute of Technology, Salem, under Anna University, Chennai, India. He received him UG degree in the discipline of Electrical a nd electronics engineering at CMS collage of Engineering, Namakkal under Anna University, Coimbatore, India .He has published and presented a number of technical papers in Technical symposiums and he got best project award in project event national level. He is the Executive member of Embedded Club at Knowledge Institute of Technology, Salem.

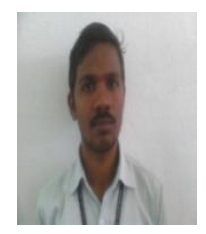

K. Govindaraju is pursuing, $P G$ in the discipline of Embedded System Technologies at Knowledge Institute of Technology, Salem, under Anna University, Chennai, India. He received his UG degree in the discipline of Electronics and Communication Engineering at KSR College Of Engineering under Anna University, Chennai, India. He has presented a number of technical papers and projects in Technical symposiums. He is the Executive Member of Embedded Club at Knowledge Institute of Technology, Salem. $\mathrm{He}$ is doing minor research works on various fields like embedded systems, Digital image processing, Renewable Energy systems and ARM Processor. He got best project award for his project in UG.

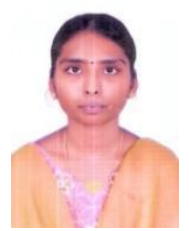

M.Sangeetha is pursuing, PG in the discipline of Embedded System Technologies at Knowledge Institute of Technology, Salem, under Anna

University Chennai, India. She received her UG degree in the discipline of Electronics and Communication Engineering at Muthayammal Engineering College, under Anna University Chennai. She is the executive member of the Embedded club at Knowledge Institute of Technology. She is highly appreciated by the head of the department.

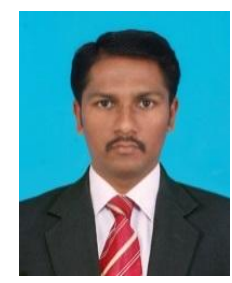

M.Jagadeeshraja is currently working as an Assistant Professor in the Department of Electrical and Electronics Engineering at Knowledge Institute of Technology, Salem. $\mathrm{He}$ received his B.E. - Electrical and Electronics Engineering Degree from Paavai Engineering College under Anna University, Chennai and M.E. - Embedded System Technologies form Academic Campus, Anna University of Technology, Coimbatore. His research includes in Embedded System, Real 
Time Operating System, and Renewable Energy Sources. He has published and presented number of technical papers in National and International conferences. He is guiding number of projects for UG and PG students.

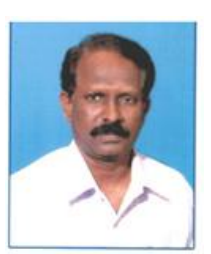

M.Dhanasu is currently working as an Assistant General Manager in the Department of Electrical at, Salem Steel Plant. He received his B.E. - Electrical and Electronics Engineering Degree from Government Engineering College under Anna University, Chennai and M.E. - Applied Electronics Government engineering College, under Anna University of Technology, Salem. His research includes in Embedded System, Re-winding of distribution transformer, industrial Drives and control, PLC, SCADA for power system. He has published and presented number of technical papers in National and International conferences. He is guiding number of projects for UG and PG students. 